\title{
Moisture Management Properties of Untreated and Scoured Cotton and Bamboo Knitted Fabrics
}

\author{
[ Nadhirah Amran, Mohd Rozi Ahmad*and Mohamad Faizul Yahya ]
}

\begin{abstract}
Moisture management properties are an important factor that could decide the comfort level of clothing worn by humans. This is largely dependent on the type of fiber and fabric structure of the fabric. In this study, the moisture management properties of untreated and scoured $100 \%$ cotton, $100 \%$ bamboo and $50 / 50 \%$ bamboo/cotton knitted fabrics were investigated. It was found that the $100 \%$ cotton and $100 \%$ bamboo fabrics, either untreated or scoured, gave good to excellent overall moisture management capability (OMMC) indicating water penetration fabric with small spreading area. The 50/50\% bamboo/cotton fabrics were graded as having poor OMMC which means that fabrics are slow in liquid absorption, drying and spreading of the liquid. It can be said that the moisture management properties depends on the fiber types and ratio of yarn combination.
\end{abstract}

Keywords-clothing comfort, moisture management properties, cotton, bamboo, knitted fabrics

\section{Introduction}

Clothing comfort refers to clothing that provides a pleasant feeling to the wearer without causing any physical problem. Comfort is also mainly related to the interaction of the human body with its microclimate and clothing [1]. The clothing work as a tampon to conserve the body temperature in different atmospheric conditions [2]. Nowadays, demand on fabric performances have changed due to the rise in living standard and technology. Consumer demands on comfortable clothing have also increased and there are many studies related to the comfort properties of fabrics. One way to achieve the level and degree of clothing comfort is through moisture management textiles [3].

Moisture management is described as the controlled movement of water vapour and perspiration from the skin to the outer surface of the fabric to make the wearer feel comfortable $[3,4]$. It is also related to the transmission behaviour of the fabric, namely air permeability, thermal behaviour of the fabric, namely air permeability, thermal conductive, water vapour permeability, moisture vapour resistance, wicking, and wetting [5-7]. All the properties mentioned above are largely influenced by the yarn, fibre and fabric properties $[5,8-11]$. These include the spinning

Nadhirah Mohd Amran, Mohd Rozi Ahmad, Mohamad Faizul Yahya Textile Research Group, Faculty of Applied Sciences, Universiti Teknologi MARA

Shah Alam, Selangor, Malaysia technology, fibre type, yarn twist, yarn count, yarn hairiness, fabric cover factors and finishing process [5].

Various studies have been conducted on the moisture management of knitted fabrics made from different fibres and blends. Troynikov \& Wardiningsih [12] investigated the liquid moisture management properties of different blended ratio of wool/polyester and wool/bamboo double layered knitted fabric that are suitable for base layer sportswear. The study found that overall the blended fabrics of wool/polyester and wool/bamboo have better moisture management properties as compared with non-blended fabrics. The blended fabrics can be classified as moisture management fabric and suitable for sportswear.

Another study by Süpüren et al. [13] worked on the moisture management of special double face knitted fabrics made from polypropylene (PP) and cotton yarn. Four types of fabrics were produced, cotton/cotton, cotton/PP, $\mathrm{PP} /$ cotton, and PP/PP for face and back sides respectively. It was found that the PP/cotton fabric gave better moisture management properties and that the fabric will reach a higher level of clothing comfort that is suitable for sports and active wear.

Studies by Kumar et al. [14] deals with the moisture management behaviour of modified polyester/wool fabrics which were treated with enzymes of either alkaline protease enzyme or acidic protease enzyme. Fabrics treated with the alkaline protease enzyme gave better result with good to excellent grade for absorption rate and spreading speed.

Prakash et al. [15] investigated the effect of fibre blend-ratio of bamboo and cotton on moisture management of single jersey knitted fabrics. They concluded that as the bamboo content increases, the wetting time, maximum wetted radius, spreading speed and overall moisture management capability (OMMC) decreases. A similar study by Majumdar et al. [16] investigated on the blend-ratio that affect the thermal properties of different knitted fabric structure namely $1 \times 1 \mathrm{rib}$, plain and interlock made from regenerated bamboo, cotton and the blended cotton/bamboo yarn. It was found that the different propotion of fibre blend gave some effect to the water vapor and air permeability of the fabrics. As the proportion of bamboo decreases, the water vapor and air permeability decreases.

Another important property in relations with clothing comfort is air permeability. Air permeability is defined as the rate of air flow throughout the fabric under 
prescribed air pressure between two surfaces of fabric [17]. Air permeability is an important factor for comfort properties which influences the flow of vapor from the human body to the environment [18].

In the present study, the moisture management properties of $1 \mathrm{x} 1$ rib made from $100 \%$ cotton, $100 \%$ bamboo and $50 / 50 \%$ bamboo/cotton yarn were investigated. The untreated fabrics are compared with scoured fabrics. Scouring was done to remove all impurities such as natural fat, wax, and oil, and improve the absorbency of the fabric.

\section{Method}

\section{A. Fabric Production and Processing}

Cotton and bamboo yarns of 30 Tex and 37 Tex were used, respectively. 1x1 rib fabrics were knitted using a circular knitting machine (Model United Texmac Pte Ltd.) with a gauge of 16 . Three different fabric samples were produced including $100 \%$ cotton yarns, $100 \%$ bamboo yarns, and a combination of 50/50\% bamboo/cotton yarns (alternately arranged in the fabric).

After the knitting process, some fabrics were left untreated while some were scoured at $100^{\circ} \mathrm{C}$ for 45 minutes using an industrial soap. All fabrics were then dried and conditioned in standard atmosphere for 24 hours to allow for relaxation and conditioning.

\section{B. Testing}

The moisture management properties of the knitted fabrics were determined using Moisture Management Tester (MMT). The instrument is commonly used to characterize fabric liquid moisture management [19]. The MMT consist of upper and lowers concentric moisture sensors which sense, measure and record the liquid moisture transport behaviours in multiple direction. Further information on the indices of MMT (see Figure 1-6) can be obtained from Troynikov \& Wardiningsih [12] and Manshahia \& Das [20]. The overall result from the instrument is called OMMC which is the overall moisture management capability. The index indicates the overall capability to manage the transport of liquid moisture in three dimensions of the fabric which are moisture absorption rate of the bottom side (BAR), one way liquid transport capacity (OWTC), and the spreading rate of bottom side $\left(\mathrm{SS}_{\mathrm{b}}\right)$. OMMC is defined as an index that indicate the overall capability to manage the transport of liquid moisture in three dimension of the fabric [13, 21].

$$
\mathrm{OMMC}=0.25 \mathrm{BAR}+0.5 \mathrm{OWTC}+0.25 \mathrm{SS}_{\mathrm{b}}
$$

The air permeability properties of the fabrics were measured using MESDAN Air-Tronic Air Permeability
Tester in accordance to ASTM D737-04/2008 at a pressure of $100 \mathrm{~Pa}$.

\section{Result and Discussion}

\section{A. Moisture Management Properties}

Table 1 shows the range of values for OMMC converted into grades. According to AATCC Test Method 195-2009 [22] the indices are graded and the value are converted into grades according to 5 grade scale (1-5). The grades of indices represent: 1 - poor, 2 - fair, 3 - good, $4-$ very good, 5 - excellent.

From Table 2, it can be seen that the $100 \%$ cotton fabric and $100 \%$ bamboo fabric have good OMMC for both untreated and scoured fabrics as both have equal grades. For the 50/50\% bamboo/cotton fabric, the values for both untreated and scoured are less than 0.2 which indicate poor OMMC. This indicates that for this fabric, the movement of water vapour and perspiration from the skin to the outer surface of the fabric is slow making it uncomfortable for the wearer.

As far as the fabric parameters are concerned, it can be seen from Table 3 that the fabric density (courses and wales per inch) for all the untreated fabrics are similar. However, for the scoured fabrics, the $100 \%$ bamboo fabric has higher courses/inch and wales/inch, indicating that after scouring, the fabric becomes denser and more compact.

Table 1. Grading specification [23]

\begin{tabular}{ccc}
\hline \multirow{2}{*}{ Rating } & \multicolumn{2}{c}{ OMMC Index } \\
\cline { 2 - 3 } & Value & Grade \\
\hline 1 & $0-0.2$ & Poor \\
2 & $0.2-0.4$ & Fair \\
3 & $0.4-0.6$ & Good \\
4 & $0.6-0.8$ & Very good \\
5 & $>0.8$ & Excellent \\
\hline
\end{tabular}

Table 2. Value and grade of OMMC of the fabrics.

\begin{tabular}{cccc}
\hline \multirow{2}{*}{ Fabric } & & \multicolumn{2}{c}{ OMMC Index } \\
\cline { 3 - 4 } & & Value & Grade \\
\hline $100 \%$ cotton & Untreated & 0.5 & Good \\
& Scouring & 0.5 & Good \\
\multirow{2}{*}{$100 \%$ bamboo } & Untreated & 0.57 & Good \\
& Scouring & 0.53 & Good \\
$50 / 50 \%$ & Untreated & 0.19 & Poor \\
bamboo/cotton & Scouring & 0.17 & Poor \\
\hline
\end{tabular}


Proc. of The Fifth Intl. Conf. On Advances in Applied Science and Environmental Engineering - ASEE 2016 Copyright (C) Institute of Research Engineers and Doctors, USA .All rights reserved.

ISBN: 978-1-63248-086-6 doi: 10.15224/ 978-1-63248-086-6-08

Table 3. Physical Properties of Knitted Fabric

\begin{tabular}{ccccccc}
\hline \multirow{2}{*}{ Fabric blends } & \multicolumn{3}{c}{$100 \%$ Cotton } & \multicolumn{2}{c}{$100 \%$ Bamboo } & \multicolumn{2}{c}{$50 / 50 \%$} \\
& Untreated & Scouring & Untreated & Scouring & Untreated & Scouring \\
\cline { 2 - 7 } & 30 & 35 & 31 & 43 & 30 & 31 \\
Courses/inch & 22 & 25 & 21 & 33 & 22 & 23 \\
Wales/inch & 1.02 & 1.13 & 0.88 & 0.97 & 0.88 & 1.09 \\
Fabric thickness (mm) & 215 & 251 & 245 & 276 & 221 & 269 \\
Fabric weight (gsm) & & &
\end{tabular}

Amongst the fabrics, the $100 \%$ bamboo fabric also has the lowest thickness but with the highest fabric weight or areal density (measured in grams per square meter) for both untreated and scoured fabrics.

The differences between the $100 \%$ cotton and $100 \%$ bamboo fabrics did not give much effect to the parameters of the 50/50\% bamboo/cotton fabric in which the yarns are alternately arranged in the fabric. Therefore, the poor result in OMMC for the 50/50\% bamboo/cotton fabric, in this case, needs further analysis and that there could be other factors that influences the moisture management result.

For a detail analysis, the fingerprint of the moisture management properties of the fabrics are given in Figure 1-6 which classifies the fabrics according to the grade for each indices. It can be seen that for the $100 \%$ cotton, both untreated and scoured, the first four indices (top wetting time, absorption rate, maximum wetted radius and spreading speed) are rated as poor. This indicates that the water penetrated through the fabric as soon as the liquid was introduced on the top surface.

As the liquid is on the other side (bottom) of the fabric, similar results were noted except for the bottom wetting time which was rated as good to very good. Overall, the OMMC was rated as good to excellent indicating that the $100 \%$ cotton fabrics is considered as water penetration fabric with small spreading area. There were some mixed results for the $100 \%$ bamboo for all the indices. However, the OMMC still gave good to excellent ratings for both untreated and scoured fabrics.

The introduction of bamboo yarns in the 50/50\% bamboo/cotton fabrics somewhat alter its moisture management properties. The liquid was able to spread on top of the fabric surface before it penetrated to the bottom surface of the fabric. As previously mentioned, for both the untreated and scoured fabrics, the OMMC ratings were poor to fair giving the expression that the fabrics are slow in absorption, drying and spreading of the liquid.

\section{B. Air Permeability}

Figure 7 shows the air permeability values of all the fabrics under study. The results indicate that untreated $50 / 50 \%$ bamboo/cotton fabrics have the highest air permeability values while the $100 \%$ cotton and $100 \%$ bamboo untreated fabrics are somewhat close and similar. The results also show that when the bamboo yarns are combined with cotton yarns, the air permeability increases. A study by Gun, Unal, \& Unal [24] on three different types of fabrics (50/50\% bamboo/cotton, 50/50\% viscose/cotton, and $50 / 50 \%$ modal/cotton) showed that air permeability is independent of the fiber type.

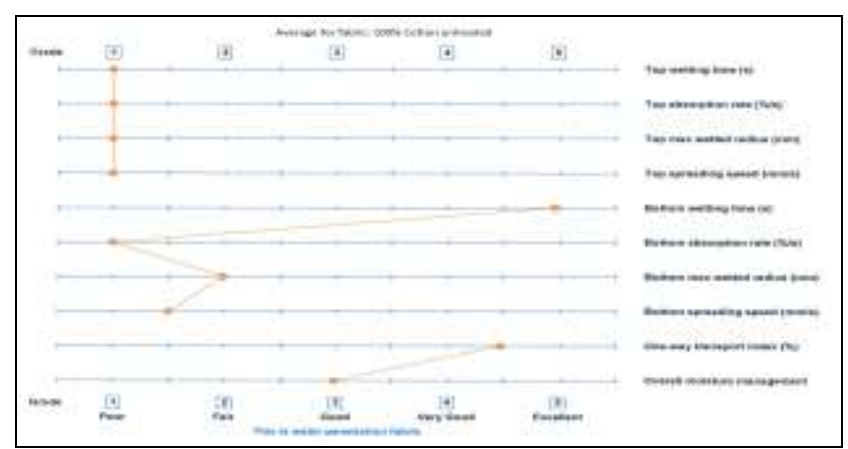

Figure 1. Fingerprint moisture management properties of $100 \%$ cotton untreated fabric

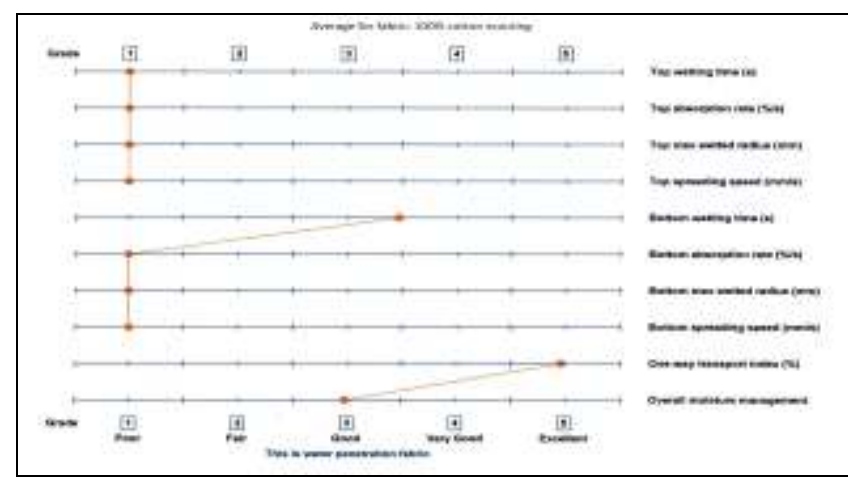

Figure 2. Fingerprint moisture management properties of $100 \%$ cotton scoured fabric

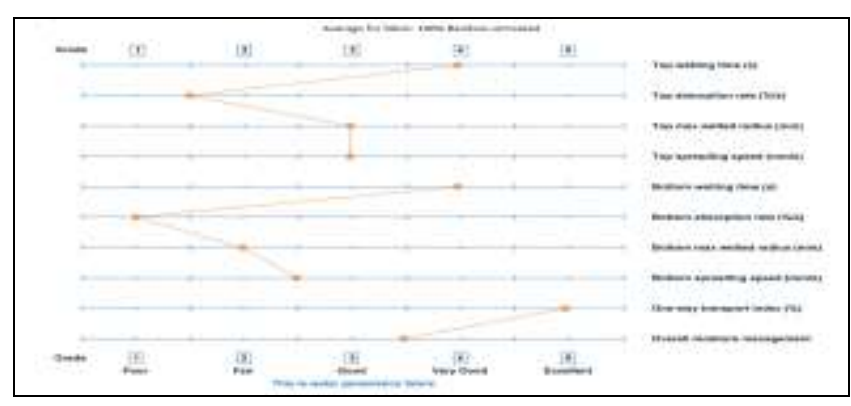

Figure 3. Fingerprint moisture management properties of $100 \%$ bamboo untreated fabric 
Proc. of The Fifth Intl. Conf. On Advances in Applied Science and Environmental Engineering - ASEE 2016 Copyright (C) Institute of Research Engineers and Doctors, USA .All rights reserved.

ISBN: 978-1-63248-086-6 doi: 10.15224/ 978-1-63248-086-6-08

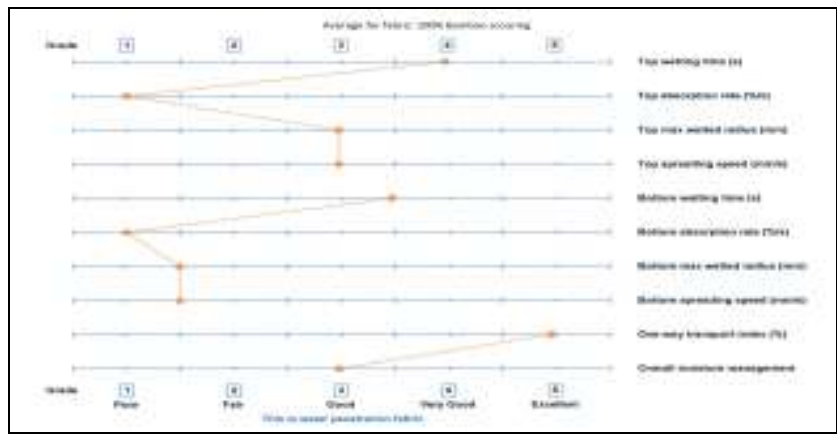

Figure 4. Fingerprint moisture management properties of $100 \%$ bamboo scoured fabric

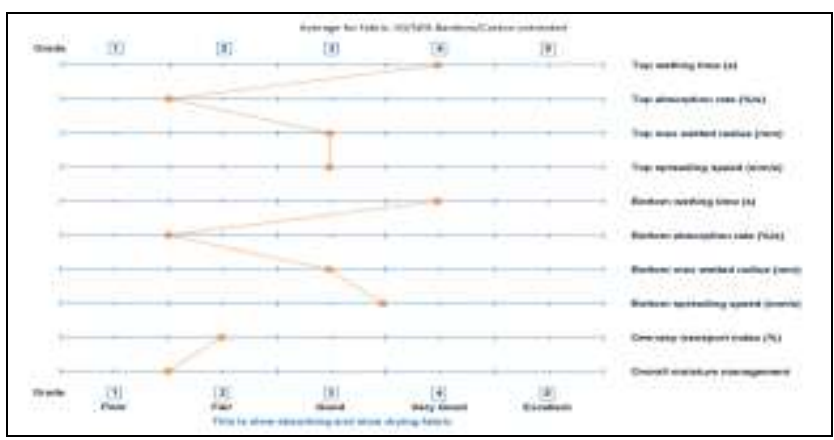

Figure 5. Fingerprint moisture management properties of $50 / 50 \%$ bamboo/cotton untreated fabric

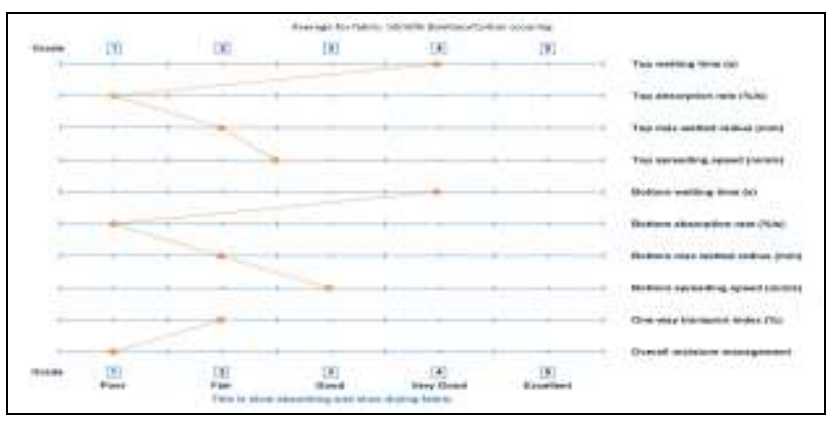

Figure 6. Fingerprint moisture management properties of $50 / 50 \%$ bamboo/cotton scoured fabric

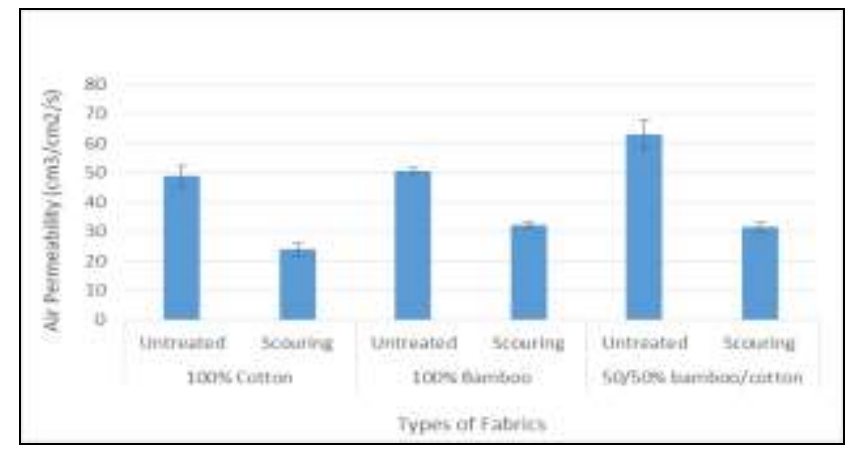

Figure 7. Air Permeability of fabric samples

It can be seen that all the untreated fabrics have higher air permeability values as compared with the scoured fabrics. This is partly due to higher course/inch, wales/inch, fabric thickness and fabric density. Once the fabrics are scoured, the fabric structure becomes tighter and hence reduces the amount of air to penetrate the fabric. According to Ramakrishnan et al. [18], the air permeability decreases as the fabric become tighter and the bamboo fiber content improve the air permeability.

\section{Conclusion}

The moisture management properties of knitted fabrics made from $100 \%$ cotton yarn, $100 \%$ bamboo yarn, and combination of bamboo/cotton yarns have been analyzed. The fabric moisture management properties such as the overall moisture management and air permeability have been studied. The types of fiber, ratio of fiber in the fabric and fabric finishing have some effect on moisture management properties. The study show that $100 \%$ cotton and $100 \%$ bamboo fabrics gave better overall moisture management capability in comparisons with fabrics consisting of both cotton and bamboo yarns. As for air permeability, the untreated fabrics in general have substantially higher air permeability than the scoured fabrics. The combined cotton/bamboo fabrics also have higher air permeability than the $100 \%$ cotton and $100 \%$ bamboo fabrics. As a conclusion, different moisture management can be achieved by using different types of yarn during the construction of fabrics.

\section{Acknowledgement}

The authors wish to thank the Research Management Center (RMC) of UiTM for the research fund under the Research Entity Initiatives (REI) Grant.

\section{References}

[1] A. Nazir, T. Hussain, F. Ahmad, and S. Faheem, "Effect of Knitting Parameters on Moisture Management and Air Permeability of Interlock Fabrics," Autex Research Journal, vol. 14, pp. 3946, 2014

[2] N. Özdil, A. Marmaral1, and S. D. Kretzschmar, "Effect of yarn properties on thermal comfort of knitted fabrics," International Journal of Thermal Sciences, vol. 46, pp. 1318-1322, 12// 2007.

[3] M. Sampath and M. Senthilkumar, "Effect of moisture management finish on comfort characteristics of microdenier polyester knitted fabrics," Journal of Industrial textiles, 2009.

[4] M. Sampath, A. Aruputharaj, M. Senthilkumar, and G. Nalankilli, "Analysis of thermal comfort characteristics of moisture management finished knitted fabrics made from different yarns," Journal of Industrial Textiles, vol. 42, pp. 19-33, 2012.

[5] J. Ajmeri and S. Bhattacharya, "Comparative Analysis Of The Thermal Comfort Properties Of Knitted Fabrics Made Of Cotton And Modal 
Proc. of The Fifth Intl. Conf. On Advances in Applied Science and Environmental Engineering - ASEE 2016

Copyright $(\subseteq$ Institute of Research Engineers and Doctors, USA .All rights reserved.

ISBN: 978-1-63248-086-6 doi: 10.15224/ 978-1-63248-086-6-08

Fibres," International Journal, vol. 3, pp. 22502378, 2013.

[6] R. Nayaka, S. Punj, K. Chatterjee, and B. Behera, "Comfort properties of suiting fabrics," Indian Journal of Fibre \& Textile Research, vol. 34, pp. 122-128, 2009.

[7] S. B. Stankovic and M. Bizjak, "Effect of Yarn Folding on Comfort Properties of Hemp Knitted Fabrics," Clothing and Textiles Research Journal, vol. 32, pp. 202-214, 2014.

[8] S. S. Mahish, A. Patra, and R. Thakur, "Functional properties of bamboo/polyester blended knitted apparel fabrics," Indian Journal of Fibre and Textile Research, vol. 37, pp. 231-237, 2012.

[9] C. Prakash, G. Ramakrishnan, and C. Koushik, "Effect of Blend Ration on Quality Characteristic of Bamboo/Cotton Blended Ring Spun Yarn," International University Journal of Science And Technology, vol. 7, pp. 34-37, 2012.

[10] N. Oğlakcioğlu and A. Marmarali, "Thermal comfort properties of some knitted structures," Fibres \& Textiles in Eastern Europe, vol. 15, pp. 64-65, 2007.

[11] A. Rathod and A. Kolhatkar, "Analysis Of Physical Characteristics Of Bamboo Fabrics," International Journal of Research in Engineering and Technology, vol. 3, pp. 21-25, 2014.

[12] O. Troynikov and W. Wardiningsih, "Moisture management properties of wool/polyester and wool/bamboo knitted fabrics for the sportswear base layer," Textile Research Journal, vol. 81, pp. 621-631, 2011.

[13] G. Süpüren, N. Oglakcioglu, N. Ozdil, and A. Marmarali, "Moisture management and thermal absorptivity properties of double-face knitted fabrics," Textile Research Journal, vol. 81, pp. 1320-1330, 2011.

[14] P. Kumar, S. K. Sinha, and S. Ghosh, "Moisture management behaviour of modified polyester wool fabrics," Fashion and Textiles, vol. 2, pp. 1-17, 2015.

[15] C. Prakash, G. Ramakrishnan, and C. Koushik, "Effect of blend proportion on moisture management characteristics of bamboo/cotton knitted fabrics," The Journal of The Textile Institute, vol. 104, pp. 1320-1326, 2013.

[16] A. Majumdar, S. Mukhopadhyay, and R. Yadav, "Thermal properties of knitted fabrics made from cotton and regenerated bamboo cellulosic fibres," International Journal of Thermal Sciences, vol. 49, pp. 2042-2048, 2010

[17] D. Gupta, V. K. Kothari, and Y. Jhanji, "Heat and moisture transport in single jersey plated fabrics," Indian Journal of Fibre \& Textile Research, vol. 39, pp. 115-121, 2014.

[18] G. Ramakrishnan, P. Umapathy, and C. Prakash, "Comfort properties of bamboo/cotton blended knitted fabrics produced from rotor spun yarns," The Journal of The Textile Institute, pp. 1-6, 2014.

[19] T. Hussain, A. Nazir, and R. Masood, "Liquid Moisture Management in Knitted Textiles-A
Review," in Conference Proceedings Page, 2015, p. 26.

[20] M. Manshahia and A. Das, "Moisture management of high active sportswear," Fibers and Polymers, vol. 15, pp. 1221-1229, 2014/06/01 2014.

[21] J. Hu, Y. Li, K.-W. Yeung, A. S. Wong, and W. $\mathrm{Xu}$, "Moisture management tester: a method to characterize fabric liquid moisture management properties," Textile Research Journal, vol. 75, pp. 57-62, 2005.

[22] A. T. M. 195-2009, "Liquid Moisture Management Properties of Textile Fabrics," 2009.

[23] Moisture Management Tester Manual, M290 MMT Moisture Management Tester: SDL Atlas Ltd, 2011.

[24] A. D. Gun, C. Unal, and B. Unal, "Dimensional and physical properties of plain knitted fabrics made from 50/50 bamboo/cotton blended yarns," Fibers and polymers, vol. 9, pp. 588-592, 2008. 